\title{
Interethnic Differences in Dementia Epidemiology: Global and Asia-Pacific Perspectives
}

\author{
N. Venketasubramanian ${ }^{a}$ S. Sahadevan ${ }^{d}$ E.H. Kua ${ }^{b}$ C.P.L. Chen ${ }^{c}$ T.-P. Ng $^{b}$ \\ aDivision of Neurology, University Medicine Cluster, and Department of Epidemiology and Public Health, \\ ${ }^{b}$ Department of Psychological Medicine, and ' ${ }^{\mathrm{C}}$ Department of Pharmacology, National University Health System, \\ National University of Singapore, and ${ }^{\mathrm{d}}$ Department of General Medicine, Tan Tock Seng Hospital, Singapore
}

\section{Key Words}

Incidence $\cdot$ Prevalence $\cdot$ Alzheimer's disease $\cdot$

Vascular dementia

\begin{abstract}
The burden of dementia will continue to rise globally, particularly in developing countries, many of which lie in the Asia-Pacific region. It was initially thought that both prevalence and incidence of dementia showed little geographic variation. More recent work has suggested differences: migrant populations attain rates between their homelands and adopted countries, and higher rates have been found in African Americans and Hispanics compared to Caucasian Whites, and also among native Australians. The only interethnic studies in the Asia-Pacific region were performed in Singapore, which showed lower standardized prevalence among ethnic Chinese compared to ethnic Malays and Indians, independent of vascular risk factors. There was conflicting information about the relative frequencies of Alzheimer's disease and vascular dementia between ethnic groups in Singapore. More research, with careful attention to potential cultural confounders, is needed to further explore and better understand interethnic differences in dementia epidemiology.

Copyright $\odot 2011$ S. Karger AG, Basel
\end{abstract}

\section{Introduction}

The burden of dementia is rising worldwide, with major medical, social and economic impacts $[1,2]$. Based on published studies and population projections, an expert panel has estimated there are 24.3 million persons with dementia in the world presently, with 4.6 million newly diagnosed cases of dementia annually, about 1 new case every 7 seconds [3]. The number of demented people is expected to double every 20 years, and reach 81.1 million by 2040 [3]. A systematic review of 36 prevalence and 15 incidence studies showed that dementia prevalence ranged from 0.3 to $1.0 \%$ among those aged $60-64$ years, increasing to $42.3-68.3 \%$ among those aged 95 years and older, while incidence varied from 0.8 to 4.0 per 1,000 person-years among those aged 60-64 years, increasing to $49.8-135.7$ per 1,000 person-years among those older than 95 years [4].

Approximately $60 \%$ of the world's population lives in the Asia-Pacific region. This region is home to many ethnic groups who may have differing disease patterns, even within a single country. This paper is a review of recent publications of dementia in the Asia-Pacific region, particularly those conducted in multiethnic populations. A Medline search was performed for the years 1966-2010,

\section{KARGER}

Fax +4161306 1234

E-Mail karger@karger.ch

www.karger.com
C) 2011 S. Karger AG, Basel

$1420-8008 / 10 / 0306-0492 \$ 26.00 / 0$

Accessible online at:

www.karger.com/dem
A/Prof. N. Venketasubramanian

Division of Neurology, University Medicine Cluster

National University Health System, National University of Singapore

$1 E$ Kent Ridge Road, NUHS Tower Block, Level 10, Singapore 119228 (Singapore)

Tel. +65 6779 5555, Fax +65 6779 4112, E-Mail ramani_nv@ @uhs.edu.sg 
combining the search term 'dementia' with the names of each of the various countries in the Asia-Pacific region, or with the phrase 'Asia-Pacific' or 'inter-ethnic' or 'multiethnic'. The abstracts were reviewed for relevance to the aim of this paper, and the original publications obtained where possible. The reference lists were also scrutinized for further relevant publications. All data were extracted by the first author and presented to the co-authors for comment and discussion. Conflicting views were resolved by consensus.

\section{Dementia in the Asia-Pacific Region}

Most people with dementia live in developing countries, approximately $60 \%$ in 2001 , and this is expected to rise to $71 \%$ by 2040 [3]. According to forecasts, the rates of increase of persons with dementia will be nonuniform across the world [3]. The numbers in developed countries are expected to double between 2001 and 2040; however, in India, China and the surrounding Western Pacific and South Asian countries, the numbers are set to quadruple [3], which is mostly attributable to population growth, greater longevity and an exponential growth of the elderly population. Dementia is the principal cause of disability among almost all low- and middle-income countries, with a median population attributable prevalence fraction of $25.1 \%$ and intersite variation largely due to differences in socioeconomic and health characteristics [5, 6]. This will place the bulk of the global burden of dementia squarely in the developing countries of the Asia-Pacific region.

\section{Geographical Variations in Dementia Prevalence Rates}

Until recently, a controversial feature of the epidemiology of dementia is the geographical variations of prevalence rates by regions and countries across the world [3]. Compared to countries in North America and Europe, lower rates of dementia were reported in the developing world. Even within low- and middle-income countries, more recent estimates show that the dementia prevalence in 65 -year-olds is high in some countries ( $>5 \%)$, but low in others such as India and sub-Saharan Africa (1-3\%) [5]. A collaborative cross-sectional survey of 14,960 subjects aged $>65$ years in 11 sites in 7 low- and middle-income countries showed that the prevalence of dementia, clinically evaluated using the Diagnostic and Statistical
Manual of Mental Disorders, 4th edition, varied widely from $0.3 \%$ in rural India to $6.3 \%$ in Cuba. After age and sex standardization, dementia prevalence in urban Latin American sites was four fifths of that in Europe, but in China the prevalence was only half, and in India and rural Latin America, a quarter or less of that in Europe [7]. Dementia prevalence using 10/66 criteria was higher and more consistent across sites, but still varies significantly between 5.6\% in rural China and $11.7 \%$ in the Dominican Republic [7].

Among countries in the Asia-Pacific region, the variation in dementia prevalence rates was consistent with the broad picture, as illustrated by recent publications of large studies [8-20] (table 1). Notwithstanding some differences in age among populations compared, there is a clear suggestion that dementia prevalence is higher in Japan and Korea, which are relatively higher income countries.

It was initially thought that methodological reasons rather than real differences accounted for geographic variations in dementia prevalence and incidence [4]. Especially in comparisons made with rates found in developing countries, major factors to be considered included differences among populations in age, gender and education, and the validity of case detection thresholds and responses to diagnostic assessments. Performance on neuropsychological tests used in screening and assessment for dementia is known to be education-dependent and there are likely cultural influences on the interpretation and reporting of symptoms and presentation of dementia. Case under-ascertainment in developing countries could possibly arise from the stigma attached to having a relative with dementia, or cognitive decline being attributed to normal aging. For example, because of the traditional Chinese belief that old people return to a childish state, dementia symptoms may be normalized [21]. Functional disability associated with cognitive decline may not be reported because of social acculturation of low expectation and demand for elder participation in daily functional roles and activities, or because it may be masked by more prominent coexisting physical morbidities. All these, and variations in the survival probabilities after the development of dementia, could possibly account for lower prevalence in developing countries.

A clearer picture has since emerged in subsequent studies with vastly enhanced data comparability that employed improved standardization methods for case ascertainment and statistical comparisons. These included comparative studies using dementia incidence. The inci- 
Table 1. Recent publications of prevalence of dementia in Asia-Pacific countries

\begin{tabular}{lllll}
\hline Country & $\begin{array}{l}\text { Publication } \\
\text { year }\end{array}$ & $\begin{array}{l}\text { Sample } \\
\text { size }\end{array}$ & $\begin{array}{l}\text { Age range } \\
\text { year }\end{array}$ & $\begin{array}{l}\text { Prevalence } \\
\%\end{array}$ \\
\hline India [8] & 2010 & 2,466 & $>55$ & 3.77 \\
China [9] & 2010 & & $>55$ & 2.99 \\
Japan [10] & 2009 & & $>65$ & 11.0 \\
Korea [11] & 2008 & 1,118 & $>65$ & 6.3 \\
Thailand [12] & 2008 & 2,311 & $>45$ & 2.35 \\
Sri Lanka [13] & 2003 & 703 & $>65$ & 3.98 \\
Australia [14] & 2001 & 146 & & 3.6 \\
Taiwan [15] & 1998 & 2,915 & $>65$ & 3.7 \\
\hline
\end{tabular}

Table 2. Recent publications of incidence of dementia in Asia-Pacific countries

\begin{tabular}{|c|c|c|c|c|c|}
\hline Country & $\begin{array}{l}\text { Publication } \\
\text { year }\end{array}$ & $\begin{array}{l}\text { Sample } \\
\text { size }\end{array}$ & $\begin{array}{l}\text { Age range } \\
\text { year }\end{array}$ & $\begin{array}{l}\text { Incidence } \\
\text { reported }\end{array}$ & $\begin{array}{l}\text { Incidence, \% } \\
\text { (annualized) }\end{array}$ \\
\hline Japan [16] & 2009 & 828 & $>65$ & $3.23 / 100$ person-years & 3.23 \\
\hline China [17] & 2008 & 1,553 & $>60$ & $0.9 \%$ at 2 years & 0.45 \\
\hline Australia [18] & 2003 & 377 & $>75$ & $16.7 \%$ at 6 years & 2.78 \\
\hline India [19] & 2001 & 2,698 & $>55$ & $0.17 / 100$ person-years & 0.17 \\
\hline
\end{tabular}

dence rates of dementia reported in Asia-Pacific countries are shown in table 2. For example, in a comparative study of Alzheimer's disease in a rural population in India and a US population comparator that employed a standardized cognitive and functional ability screening, clinical evaluation using the Diagnostic and Statistical Manual of Mental Disorders (4th edition), and the $\mathrm{Na}-$ tional Institute of Neurological and Communicative Disorders and Stroke-Alzheimer's Disease and Related Disorders Association criteria for the diagnosis, and the Clinical Dementia Rating scale for the staging of dementia and Alzheimer's disease showed that the age-standardized incidence rate of Alzheimer's disease in those aged $\geq 65$ years ( 4.7 per 1,000 person-years) was substantially lower than the corresponding rate (17.5 per 1,000 person-years) in the US study population [19].

It is clearly apparent now that intercountry and intracountry regional variations in rates of dementia exist that are not simply due to differences in ascertainment protocols and lack of statistical standardization of rates. Results from the 10/66 Dementia Research Group population-based surveys are an example of many such studies that support this premise. The documentation of sub- stantial population heterogeneity in the risks and duration of dementia suggests the importance of studying genetic, environmental risk and protective factors; cultural factors in the etiology and natural progression of dementia; and preventive approaches in reducing the burden of dementia $[5,6]$.

\section{Interethnic Variations in Dementia Rates}

The investigation of within-country ethnic variations in dementia rates has potentially great implications for etiological research as well as for service planning and resource allocation. Genetic and environmental factors, including lifestyle, social and cultural factors (e.g. diet, nutrition, physical, mental and social activities), and cardiovascular risk factors, as well as their complex interactions [22] are some of the important repercussions of such research [23]. There is much value from such comparative studies in uncovering the presence or higher frequencies of protective factors or the absence or relatively low frequencies of risk factors that underlies interethnic differences. 
Table 3. Multiethnic community-based dementia prevalence studies in Singapore

\begin{tabular}{|c|c|c|c|c|c|}
\hline Characteristic & $\begin{array}{l}\text { Study } 1 \\
{[26]}\end{array}$ & & $\begin{array}{l}\text { Study } 2 \\
{[27]}\end{array}$ & & $\begin{array}{l}\text { Study } 3 \\
{[28]}\end{array}$ \\
\hline $\begin{array}{l}\text { Publication year } \\
\text { Sample size }\end{array}$ & \multicolumn{2}{|l|}{1995} & \multicolumn{2}{|l|}{2008} & 2010 \\
\hline Total & \multicolumn{2}{|l|}{349} & \multicolumn{2}{|l|}{14,817} & 995 \\
\hline Chinese & \multicolumn{2}{|l|}{200} & \multicolumn{2}{|l|}{8,849} & 479 \\
\hline $\begin{array}{l}\text { Malay } \\
\text { Indian }\end{array}$ & \multicolumn{2}{|l|}{149} & \multicolumn{2}{|l|}{$\begin{array}{l}3,053 \\
2,915\end{array}$} & $\begin{array}{l}300 \\
216\end{array}$ \\
\hline Age group, years & \multicolumn{2}{|l|}{$>65$} & \multicolumn{2}{|l|}{$>50$} & $\begin{array}{l}210 \\
>60\end{array}$ \\
\hline \multicolumn{6}{|c|}{ Prevalence, $\%$} \\
\hline Overall & \multicolumn{2}{|l|}{3.2} & \multicolumn{2}{|l|}{1.26} & 5.2 \\
\hline Chinese & \multicolumn{2}{|l|}{2.5} & \multicolumn{2}{|l|}{1.19} & 4.2 \\
\hline Malay & \multicolumn{2}{|l|}{4.0} & \multicolumn{2}{|l|}{1.56} & 9.4 \\
\hline Indian & \multicolumn{2}{|l|}{ ND } & \multicolumn{2}{|l|}{1.93} & 8.8 \\
\hline \multirow[t]{10}{*}{ Subtype } & \multicolumn{2}{|l|}{$A D$} & \multicolumn{2}{|l|}{$A D$} & - \\
\hline & Chinese F & 1.8 & Chinese & 0.60 & \\
\hline & Chinese $\mathrm{M}$ & 1.1 & Malay & 0.91 & \\
\hline & Malay F & 1.5 & Indian & 0.89 & \\
\hline & Malay M & 1.2 & & & \\
\hline & MID & & $V D$ & & \\
\hline & Chinese F & 0.9 & Chinese & 0.55 & \\
\hline & Chinese M & 1.1 & Malay & 0.52 & \\
\hline & Malay F & 4.4 & Indian & 0.87 & \\
\hline & Malay M & 1.2 & & & \\
\hline
\end{tabular}

$\mathrm{ND}=$ Not done $\mathrm{AD}=$ Alzheimer's disease MID = multi-infarct dementia; $\mathrm{VD}=$ vascular dementia; $\mathrm{F}=$ female; $\mathrm{M}=$ male.

There are, however, few published reports of studies of interethnic differences which use population-based sampling and standardized methods of dementia case ascertainment. The handful of such interethnic studies include studies in the northern Manhattan areas of New York City of 3 ethnic groups of Caribbean Hispanics, African Americans and non-Latino Whites [24, 25], and in smaller populations in Singapore with multiethnic communities of Chinese, Malays and Indians [26-28].

\section{North American Studies}

In the northern Manhattan study in New York City, dementia prevalence was found to be higher in African Americans and Latinos than in non-Latino Whites [24]. The level of education was found to be strongly associated with rates of dementia and, when age and education were simultaneously controlled, ethnic differences in rates were no longer consistently found. As well, in a separate study, the incidence of Alzheimer's disease was found to be increased twofold among African-American and Caribbean-Hispanic individuals compared to White individuals [25]. The disproportionate risks among the 3 ethnic groups were not entirely explained by differences in number of years of education, illiteracy or history of stroke, hypertension, heart disease or diabetes. Another study has reported that Native Americans may have a later age of onset compared to Whites [29].

\section{Asia-Pacific Studies}

Interethnic studies in other countries with different ethnic make-ups and environmental influences have been reported in Australia and Singapore. Dementia prevalence has been found to be higher among Indigenous Australians compared to the general Australian population [30]. In that study, it was not possible to determine whether factors such as education, lifestyle and cardiovascular factors explained the higher rates of dementia among Indigenous Australians.

The only other reports that have explored interethnic differences in dementia prevalence have come from studies in the multiethnic population (5 million) of Singapore. Chinese make up the major ethnic group in Singapore, comprising $74.2 \%$ of the resident population, while Malays comprise $13.4 \%$, Indians $9.2 \%$ and other ethnicities account for $3.2 \%$ [31]. The first of these 3 population-based comparative studies of dementia was done roughly 20 years ago and the other 2 studies were completed over the last 2 years [26-28] (table 3). These studies were conducted independently by different investigators and vary in sample size, inclusion age, screening and diagnostic instruments, hence the overall prevalence of dementia varied according to the screening and diagnostic thresholds for case ascertainment. Despite these differences, all studies were remarkably consistent in finding within and across studies that dementia prevalence was lowest among ethnic Chinese, compared to ethnic Malays and ethnic Indians. Ethnic differences in dementia prevalence were not explained by differences in gender, age or education [28]. Although differences in cardiovascular factors (hypertension, diabetes, cardiovascular diseases, stroke and smoking), depression and leisure time activities contributed to the differences (but only modestly), significant ethnic differences remained. However, differences in Mini-Mental State Examination scores contributed the most in explaining almost all the 
ethnic differences, suggesting that innate or acquired cognitive ability and functional reserve accounted for much of the ethnic differences in dementia prevalence [28].

\section{Lifestyle Factors}

The small number of interethnic comparison studies of dementia suggest that much remains to be understood about the onset and course of dementia, which takes decades to develop. In line with the life course approach to dementia epidemiology, environmental, social, physical and other influences throughout an individual's life span are likely to vary among ethnic groups and contribute differently to the level of cognitive functional reserve which predisposes to the development of dementia [32].

The selectively lower risks of dementia among population groups such as Japanese, Chinese and rural Indians are intriguing, and suggest that some possibly unique elements of Asian lifestyles, including traditional dietary patterns (low in calories, saturated fats, meat, full-fat dairy products, refined carbohydrates, sugar and salt, but high in vegetables and fruits, tea and spices that are phytonutrient- and antioxidant-rich) that minimize vascular risks for dementia development or confer neuroprotection, may be an important contributing factor [33]. They are paradigmatic for research in dietary and nutritional factors (such as folate, fish and omega- 3 fatty acids consumption, tea, turmeric, etc.) that have been shown by a growing body of evidence to contribute to the level of cognitive functioning and the risks of cognitive decline [34].

\section{Dementia in Migrant Populations}

The important roles played by environmental factors, including diet, in dementia risks are strongly illustrated by migrant studies of Japanese who migrated from their place of birth. Reported incidence rates of dementia among elderly Japanese who emigrated to Brazil before World War II (34.2 per 1,000 person-years) [35] and prevalence rates among Japanese-Brazilians aged above 70 years (12.1\%) [36], as well as among Japanese aged above 65 years in the state of Washington, USA (6.3\%) [37], and among Japanese men aged above 70 years in Hawaii, USA (7.6\%) [38], are higher than those found in their native homeland Japan and closer to their adopted countries.
Another study that compared dementia incidence among elderly Yoruba residing in Nigeria (i.e. Nigerian Africans) to African Americans showed a much lower incidence among the former (1.35 vs. 3.24\%) [39].

\section{APOE Genotypes}

The frequency of the $A P O E-\varepsilon 4$ allele, a known risk factor for Alzheimer's disease, is an important genetic risk factor explaining ethnic differences. This has been found to be low (7.3\%) in an Indian rural population sample as compared with an American population sample (11\%) [19] and other Western populations. However, the association of the $A P O E \varepsilon 4$ allele with Alzheimer's disease or non-Alzheimer's disease dementia has been shown to vary among different ethnic groups, suggesting selective survival of carriers of different APOE alleles for different ethnic populations. For example, it is weaker for African Americans than for Hispanics and Whites, and was null in native Nigerians; however, the $A P O E-\varepsilon 2 / \varepsilon 3$ genotype was associated with an increased risk of Alzheimer's disease in African Americans but with reduced risk in Whites [40].

Studies of ethnic differences in Singapore so far have lacked data on $A P O E$ status to determine its link with dementia risks among the different ethnic groups. In other nondementia-related studies, Malays have been reported to show the highest frequency of the $\varepsilon 4$ allele, whereas $\varepsilon 2$ was least common in Indians [41]. Estimates of the strength of association of the APOE $\varepsilon 4$ genotype with dementia and its variations among the ethnic groups in Singapore are still unavailable and should be further investigated.

The issue of how to determine race and ethnicity has significant implications on biomedical research, particularly where it is possible that biological factors may explain disparities seen in health status. Genetic studies could contribute to this particular line of research where mixed ethnicity is likely. Population stratification in association studies can be controlled for by estimating genetic ancestry, which may also help detect a biological basis for causation for population-specific differences in disease [42]. The confounding effects due to population stratification may be accounted for by using large numbers of unselected genome-wide single nucleotide polymorphisms. An alternative is to use selected panels of ancestry informative markers $[43,44]$. These approaches may be further enhanced by employing appropriate statistical methods [45]. 


\section{Conclusions}

The societal burden due to dementia is set to grow to epidemic proportions among countries in the Asia-Pacific region. Information on possible interethnic differences are emerging, but more in-depth collaborative studies are needed to address important methodological issues, especially dementia incidence studies that pay close atten- tion to cultural factors that can affect dementia recognition [46]. For the foreseeable future, appropriately targeted interventions for lifestyle and behavioral factors for dementia appear to hold good prospects for dementia prevention, but treatment of genetic factors are likely to remain elusive. Every effort to reduce the global impact of dementia is a worthwhile investment.

\section{References}

1 Larson EB, Langa KM: The rising tide of dementia worldwide. Lancet 2008;372:430432.

12 Cotter VT: The burden of dementia. Am J Manag Care 2007;13(Suppl 8):S193-S197.

$>3$ Ferri CP, Prince M, Brayne C, et al: Global Prevalence of dementia: a Delphi consensus study. Lancet 2005;366:2112-2117.

$>4$ Fratiglioni L, De Ronchi D, Agüero-Torres $\mathrm{H}$ : Worldwide prevalence and incidence of dementia. Drugs Aging 1999;15:365-375.

$>5$ Kalaria RN, Maestre GE, Arizaga R, Friedland RP, Galasko D, Hall K, Luchsinger JA, Ogunniyi A, Perry EK, Potocnik F, Prince M, Stewart R, Wimo A, Zhang ZX, Antuono P, World Federation of Neurology Dementia Research Group: Alzheimer's disease and vascular dementia in developing countries: prevalence, management, and risk factors. Lancet Neurol 2008;7:812-826.

6 Sousa RM, Ferri CP, Acosta D, Albanese E, Guerra M, Huang Y, Jacob KS, Jotheeswaran AT, Rodriguez JJ, Pichardo GR, Rodriguez MC, Salas A, Sosa AL, Williams J, Zuniga T, Prince M: Contribution of chronic diseases to disability in elderly people in countries with low and middle incomes: a 10/66 Dementia Research Group population-based survey. Lancet 2009;374:1821-1830.

7 Llibre Rodriguez JJ, Ferri CP, Acosta D, Guerra M, Huang Y, Jacob KS, Krishnamoorthy ES, Salas A, Sosa AL, Acosta I, Dewey ME, Gaona C, Jotheeswaran AT, Li S, Rodriguez D, Rodriguez G, Kumar PS, Valhuerdi A, Prince M, 10/66 Dementia Research Group: Prevalence of dementia in Latin America, India, and China: a population-based cross-sectional survey. Lancet 2008;372:464-474.

$>8$ Mathuranath PS, Cherian PJ, Mathew R, Kumar S, George A, Alexander A, Ranjith N, Sarma PS: Dementia in Kerala, South India: prevalence and influence of age, education and gender. Int J Geriatr Psychiatry 2010;25: 290-297.

$\checkmark 9$ Zhao Q, Zhou B, Ding D, Guo Q, Hong Z: Prevalence, mortality, and predictive factors on survival of dementia in Shanghai, China. Alzheimer Dis Assoc Disord 2010;24:151158.
0 Wada-Isoe K, Uemura Y, Suto Y, Doi K, Imamura K, Hayashi A, Kitayama M, Watanabe Y, Adachi Y, Nakashima K: Prevalence of dementia in the rural island town of Amacho, Japan. Neuroepidemiology 2009;32: 101-106.

11 Jhoo JH, Kim KW, Huh Y, Lee SB, Park JH, Lee JJ, Choi EA, Han C, Choo IH, Youn JC, Lee DY, Woo JI: Prevalence of dementia and its subtypes in an elderly urban Korean population: results from the Korean Longitudinal Study on Health And Aging (KLoSHA). Dement Geriatr Cogn Disord 2008;26:270 276.

12 Wangtongkum S, Sucharitkul P, Silprasert $\mathrm{N}$, Inthrachak R: Prevalence of dementia among population aged over 45 years in Chiang Mai, Thailand. J Med Assoc Thai 2008; 91:1685-1690.

13 de Silva HA, Gunatilake SB, Smith AD: Prevalence of dementia in a semi-urban population in Sri Lanka: report from a regional survey. Int J Geriatr Psychiatry 2003; 18:711-715.

14 Snowdon J, Lane F: The prevalence and outcome of depression and dementia in Botany's elderly population. Int J Geriatr Psychiatry 2001;16:293-299.

15 Lin RT, Lai CL, Tai CT, Liu CK, Yen YY, Howng SL: Prevalence and subtypes of dementia in southern Taiwan: impact of age, sex, education, and urbanization. J Neurol Sci 1998;160:67-75.

16 Matsui Y, Tanizaki Y, Arima H, Yonemoto K, Doi Y, Ninomiya T, Sasaki K, Iida M, Iwaki T, Kanba S, Kiyohara Y: Incidence and survival of dementia in a general population of Japanese elderly: the Hisayama study. J Neurol Neurosurg Psychiatry 2009;80:366-370.

$\checkmark 17$ Li S, Yan F, Li G, Chen C, Zhang W, Liu J, Jia $\mathrm{X}$, Shen $\mathrm{Y}$ : Is the dementia rate increasing in Beijing? Prevalence and incidence of dementia 10 years later in an urban elderly population. Acta Psychiatr Scand 2007;115:73-79.

18 Piguet O, Grayson DA, Creasey H, Bennett HP, Brooks WS, Waite LM, Broe GA: Vascular risk factors, cognition and dementia incidence over 6 years in the Sydney Older Persons Study. Neuroepidemiology 2003;22: 165-171.
19 Chandra V, Pandav R, Dodge HH, Johnston JM, Belle SH, DeKosky ST, Ganguli M: Incidence of Alzheimer's disease in a rural community in India: the Indo-US study. Neurology 2001;57:985-989.

20 Liu CK, Lai CL, Tai CT, Lin RT, Yen YY, Howng SL: Incidence and subtypes of dementia in southern Taiwan: impact of sociodemographic factors. Neurology 1998;50: 1572-1579.

21 Ikels C: The experience of dementia in China. Cult Med Psychiatry 1998;22:257-283.

22 Weiner MF: Perspective on race and ethnicity in Alzheimer's disease research. Alzheimers Dement 2008;4:233-238.

23 Graham C, Howard R, Ha Y: Dementia and ethnicity. Int Psychogeriatr 1998;10:183-191.

24 Gurland BJ, Wilder DE, Lantigua R, Stern Y, Chen J, Killeffer EH, Mayeux R: Rates of dementia in three ethnoracial groups. Int J Geriatr Psychiatry 1999;14:481-493.

25 Tang MX; Cross P, Andrews H, et al: Incidence of AD in African-Americans, Caribbean Hispanics, and Caucasians in northern Manhattan. Neurology 2001;56;49-56.

26 Kua EH, Ko SM: Prevalence of dementia among elderly Chinese and Malay residents of Singapore. Int Psychogeriatr 1995;7:439-446.

27 Sahadevan S, Saw SM, Gao W, Tan LC, Chin JJ, Hong CY, Venketasubramanian N: Ethnic differences in Singapore's dementia prevalence: the stroke, Parkinson's disease, epilepsy, and dementia in Singapore study. J Am Geriatr Soc 2008;56:2061-2068.

28 Ng TP, Leong T, Chiam PC, Kua EH: Ethnic variations in dementia: the contributions of cardiovascular, psychosocial and neuropsychological factors. Dement Geriatr Cogn Disord 2010;29:131-138.

29 Weiner MF, Rosenberg RN, Svetlik D, Hynan LS, Womack KB, White C 3rd, Good S, Fuller C, Wharton D, Richter R: Comparison of Alzheimer's disease in Native Americans and Whites. Int Psychogeriatr 2003;15:367375.

30 Smith K, Flicker L, Lautenschlager NT, Almeida OP, Atkinson D, Dwyer A, LoGiudice D: High prevalence of dementia and cognitive impairment in Indigenous Australians. Neurology 2008;71:1470-1473. 
31 Department of Statistics, Government of Singapore. http://www.singstat.gov.sg

32 Whalley LJ, Dick FD, McNeill G: A lifecourse approach to the aetiology of late-onset dementias. Lancet Neurol 2006;5:87-96.

33 Lee MS, Wahlqvist ML: Population-based studies of nutrition and health in Asia-Pacific elderly. Asia Pac J Clin Nutr 2005;14:294297.

34 Kamphuis PJ, Scheltens P: Can nutrients prevent or delay onset of Alzheimer's disease? J Alzheimers Dis 2010;20:765-775.

35 Meguro K, Chubaci RY, Meguro M, Kawamorida K, Goto N, Caramelli P: Incidence of dementia and cause of death in elderly Japanese emigrants to Brazil before World War II. Arch Gerontol Geriatr 2010, E-pub ahead of print.

36 Yamada T, Kadekaru H, Matsumoto S, Inada $\mathrm{H}$, Tanabe M, Moriguchi EH, Moriguchi Y, Ishikawa P, Ishikawa AG, Taira K, Yamori Y: Prevalence of dementia in the older Japanese-Brazilian population. Psychiatry Clin Neurosci 2002;56:71-75.
7 Graves AB, Larson EB, Edland SD, Bowen JD, McCormick WC, McCurry SM, Rice MM, Wenzlow A, Uomoto JM: Prevalence of dementia and its subtypes in the Japanese American population of King County, Washington state. The Kame Project. Am J Epidemiol 1996;144:760-771.

38 White L, Petrovitch H, Ross GW, Masaki $\mathrm{KH}$, Abbott RD, Teng EL, Rodriguez BL, Blanchette PL, Havlik RJ, Wergowske G, Chiu D, Foley DJ, Murdaugh C, Curb JD: Prevalence of dementia in older JapaneseAmerican men in Hawaii: The HonoluluAsia Aging Study. JAMA 1996;276:955-960.

-39 Hendrie HC, Ogunniyi A, Hall KS, Baiyewu O, Unverzagt FW, Gureje O, Gao S, Evans $\mathrm{RM}$, Ogunseyinde AO, Adeyinka AO, Musick B, Hui SL: Incidence of dementia and Alzheimer disease in 2 communities: Yoruba residing in Ibadan, Nigeria, and African Americans residing in Indianapolis, Indiana. JAMA 2001;285:739-747.

40 Osuntokun BO, Sahota A, Ogunniyi AO, Gureje O, Baiyewu O, Adeyinka A, Oluwole SO, Komolafe O, Hall KS, Unverzagt FW, Hui SL, Yang M, Hendrie HC: Lack of association between apolipoprotein $\mathrm{E} \mathrm{e} 4$ and $\mathrm{Alz}$ heimer's disease in elderly Nigerians. Ann Neurol 1995;38:463-465.
41 Tan CE, Tai ES, Tan CS, Chia KS, Lee J, Chew SK, Ordovas JM: APOE polymorphism and lipid profile in the Singapore population. Atherosclerosis 2003;170:253-260.

42 Via M, Ziv E, Burchard EG: Recent advances of genetic ancestry testing in biomedical research and direct to consumer testing. Clin Genet 2009;76:225-235.

43 Tian C, Gregersen PK, Seldin MF: Accounting for ancestry: population substructure and genome-wide association studies. Hum Mol Genet 2008;17(R2):R143-R150.

44 Enoch MA, Shen PH, Xu K, Hodgkinson C, Goldman D: Using ancestry-informative markers to define populations and detect population stratification. J Psychopharmacol 2006;20(Suppl 4):19-26.

45 Tiwari HK, Barnholtz-Sloan J, Wineinger N, Padilla MA, Vaughan LK, Allison DB: Review and evaluation of methods correcting for population stratification with a focus on underlying statistical principles. Hum Hered 2008;66:67-86.

-46 Manly JJ, Espino DV: Cultural influences on dementia recognition and management. Clin Geriatr Med 2004;20:93-119. 